
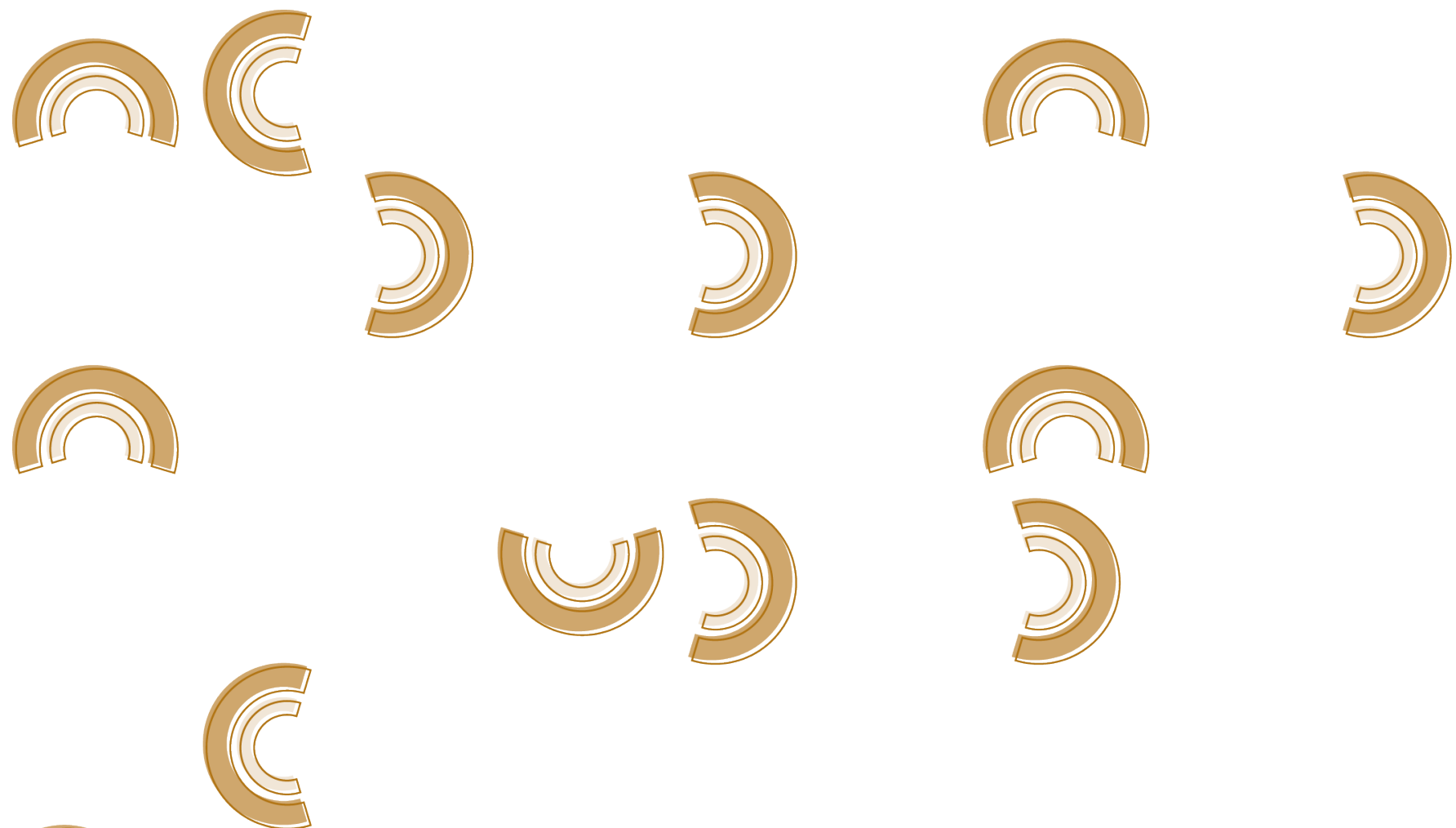

Dossiê Dramaturgia da DANÇA

\title{
As Dramaturgias do Movimento
}

\section{Rosa Hercoles}

Atua como eutonista e dramaturgista da dança. Possui mestrado e doutorado em Comunicação e Semiótica pela PUCSP. É professora do curso de Comunicação das Artes do Corpo e integrante do Centro de Estudos em Dança, ambos na PUCSP. 


\section{RESUMO}

Esse artigo se dedicará à apresentação de algumas questões, julgadas necessárias à construção de entendimentos relativos às dramaturgias da dança, tais como: a natureza dos gestos simbólicos, o problema corpo-mente e a especialização do movimento.

Palavras-chave: o corpo que dança, Movimento em dança, Dramaturgia da dança.

\section{ABSTRACT}

This article will be dedicated to the presentation of some questions, considered necessary for the construction of understandings related to dance dramaturgies, such as: the nature of symbolic gestures, the body-mind problem and the specialization of movement.

Keywords: Body dancing, Movement in dance, Dramaturgy of dance. 
á muito se sabe que as discussões relativas às dramaturgias da dança surgiram na segunda metade do século 18; ocasião em que vários coreógrafos, intitulados à época como mestres de balé, estavam muito interessados em investigar aquilo que a dança poderia, ou não, expressar.

Muitas pesquisas foram desenvolvidas nesse período, mas, graças à publicação de uma série de cartas, ${ }^{2}$ em 1760, escritas pelo coreógrafo francês JeanGeorges Noverre (1727-1810), hoje, se pode acessar, com precisão, as questões levantadas naquele período da dança. Esse mesmo coreógrafo propôs uma solução para os problemas levantados, relativos ao potencial comunicativo do balé barroco, e a hipótese formulada foi a de que técnica e expressividade deveriam ser entendidas como instâncias inerentes à materialidade movimento. Para ele, a expressão não é algo que agregamos aos movimentos despidos da possibilidade de possuírem seus próprios significados, mas, sim, algo que formalmente os constitui. Por exemplo, um corpo que cai: nos conta que está caindo, e a forma como cai é que irá comunicar o seu sentido. Teremos coisas muito distintas sendo expressas/comunicadas se essa queda for contínua ou descontínua, rápida ou lenta, com ou sem pausas, com mais ou menos peso, direta ou indireta, etc., etc. Ao longo da história da dança, tal hipótese foi adotada por inúmeras composições coreográficas e, hoje, apresenta-se como questão pacificada, pelo menos entre historiadores e teóricos da dança.

Se partirmos do pressuposto que coreografia (relações espaço-tempo) e dramaturgia (relações forma-sentido) são fenômenos inseparáveis e simultâneos que ocorrem no corpo que dança, enquanto ele dança, se faz necessário olharmos para o modo como essas relações se estabelecem, bem como para os problemas que alguns procedimentos, historicamente consolidados, ocasio-
1 MONTEIRO, Mariana. Noverre-cartas sobre a dança. São Paulo: Edusp, 1998. 
nam. Sobretudo, no Brasil, aonde a grande maioria dos corpos foi, e continua sendo, formada dentro de perspectivas romântico/modernistas. Essas perspectivas amplamente difundidas, através dos processos didático-pedagógicos adotados pelo ensino do balé clássico e pelas técnicas de dança moderna, são responsáveis por veicular a ideia de que aquilo que se expressa é de natureza distinta à materialidade do movimento e que, consequentemente, não se reduz a ele. Talvez, essa tradição elucide o porquê, até os dias de hoje, a dramaturgia é pensada, por alguns, como algo que posteriormente se adiciona à coreografia (erroneamente, restringida à simples sucessão de passos); ou, ainda, que ela é concernente à organização da cena e não à do movimento.

Cabe ressaltar que uma coisa é abordar a coreografia e a dramaturgia isoladamente para fins do desenvolvimento de estudos que promovam o reconhecimento de suas especificidades, outra é separá-las como ocorrências não relativas à materialidade do corpo em movimento. Seria o mesmo que pensar ribossomos e mitocôndrias como coisas passíveis de serem subtraídas do contexto célula. Essa lógica dual nos leva à primeira questão que gostaria de levantar e que diz respeito àquilo que os Cientistas Cognitivos enunciam como o problema corpo-mente. ${ }^{2}$

\section{O PERSISTENTE DUALISMO ENTRE CORPO E MENTE}

O filósofo da mente Paul Churchland $(1998)^{3}$ nos diz que todos os argumentos que propõem a existência de algo que não se reduz à materialidade e às operações realizadas pelo corpo difundem pressupostos dualistas. Todos fundados na doutrina cartesiana de que há uma dimensão não-física que se conecta de modo determinista causal à dimensão física. A defesa da existência de uma dimensão que se encontra além da fisicalidade se dá devido à impossibilidade, segundo os pressupostos mecanicistas vigentes, no século 17, de se quantificar os fenômenos mentais. Por exemplo: quanto pesa um pensamento? Ou, qual a extensão da consciência? Embora, esse dualismo de substâncias não mais se sustente cientificamente, seus argumentos são atualizados, segundo Churchland, no que ele chamou de dualismos de propriedades, em que os fenômenos mentais são tratados como acontecimentos não redutíveis às atividades eletroquímicas do cérebro. Como se aquilo que o cérebro produz não fosse regido por leis físicas, como se aquilo que nele ocorre fosse de outra natureza, possuidora de maior valor. Perpetuando-se, desse modo, as relações absolutamente hierárquicas entre corpo e mente, o corpo e suas ações vistos como algo menor, o corpo e seu cérebro vistos como simples informantes, instrumentos ou veículos que garantem a ocorrência de algo maior, algo que não se reduz à sua fisicalidade.
2 CHURCHLAND, Paul M. Matéria e Consciência - uma introdução contemporânea à filosofia da mente São Paulo: Unesp, 1998.

3 Idem. 
Infelizmente, entendimentos desta ordem são vencedores em nossa cultura e nenhum de nós, incluindo a dança, está imune aos seus efeitos nefastos. Por anos tivemos que ouvir leituras que enunciavam que a excelência do dançarino residia no fato dele ser capaz de superar a técnica, ou seja, aquilo que ele expressava encontrava-se além do fazer de seu próprio corpo. Esse $d u$ alismo de substância de algum modo foi superado pela dança, mas, também, foi atualizado no enunciado de que algo ocorre "entre". Contudo, parece-me que esse "entre" tem sido a forma encontrada para continuar dizendo que aquilo que o movimento expressa/comunica não pode ser reduzido a ele mesmo, um tipo de discurso que indica a presença de uma variação do dualismo de propriedades. Proponho que, para escaparmos dos dualismos, esse "entre" necessita ser pensado de outro modo. De fato, há algo entre se o entendemos como mediação, porém, quem faz essa mediação é a percepção e as representações mentais dela advinda, ou seja, processos que ocorrem na carne tanto daquele que exprime quanto daquele que acessa e reconhece aquilo que é expresso.

Outra questão relevante se coloca quando as dramaturgias são pensadas a partir de perspectivas dualistas. Tributário desses dualismos, o mito da criação enquanto espaço de "liberdade absoluta" reina com preocupante vigor em terras onde a dúvida, inerente aos processos investigativos, não tem lugar. Talvez, de partida, devêssemos abandonar o termo criação e adotar o de produção, como sugere Agamben (2018). ${ }^{4}$ Isto, porque, o termo criação, largamente adotado pelas religiões, inexoravelmente, se relaciona a algum tipo de ato divino; e, portanto, enquanto divindade, da ordem do não-físico.

Se o corpo em movimento é tido como meio de produção de linguagens em dança, é preciso aceitar o fato de que ele, apesar de possuir várias possibilidades, também possui inúmeras restrições. Ou seja, possibilidades expressivas não são infinitas, mas, sim, estarão restritas pelo meio que as implementa. A exemplo do corpo construído pelo Balé Romântico, cujo ideário de transcendência da matéria, movido pelo desejo de voar, teve que se (con) formar à possibilidade de subir nas pontas.

Outro fantasma que continua rondando alguns discursos essencialistas é o de que a delimitação das questões que se pretende investigar inibiria o processo "criativo" de se manter livre, leve e solto. Contudo, ideias sem lastro na realidade do corpo perpetuam o acordo tácito de que o ato criativo possui uma instância não-física. Assim sendo, não é de se estranhar a construção coreográfica a partir de temas, que serão ilustrados pelo corpo através da apresentação de situações ancoradas em estados de presença predominantemente psicoemocionais, dotados de uma expressividade modernista amenizada para poderem ser enunciados como contemporâneos.
4 ACAMBEN, Giorgio. "O que é o ato de criação" em O Fogo e o Relato - ensaios sobre criação, escrita, arte e livros. São Paulo: Boitempo, 2018. 
Não podemos nos esquivar da evidência de que somente conseguimos produzir a partir dos materiais que estão disponíveis, e, isso, nos leva à questão do repertório. Não podemos desconsiderar, também, o fato de que esses repertórios se estabelecem através dos treinamentos aos quais os corpos se submetem e que, por sua vez, irão constituir um conjunto de preferências neuromusculares, responsáveis pela restrição de possibilidades. Assim, ao se movimentar, aquilo que o corpo escolhe já está de algum modo por ele escolhido.

Se a discussão pretendida ocorre na materialidade do corpo em movimento, e não fora dele, a necessidade de revisão do repertório, previamente consolidado pelos treinamentos técnicos, se faz necessária. A revisão de modelos de conduta não é uma tarefa fácil; revisar implica na exploração de outras possibilidades de ação e na construção de outros padrões de movimento, de modo a escapar da restrição imposta pelos modelos incorporados. Isso não quer dizer que treinamentos são dispensáveis, eles nos ajudam a entender o modo como os movimentos se constroem dentro de um determinado recorte, bem como as lógicas que fundam suas proposições estéticas. Mas não é possível pensar o corpo como experiência do presente sem enfrentarmos o problema trazido pelo repertório pré-existente ao processo de produção, pois, sem essa reflexão, a estratégia da improvisação como método de investigação torna-se completamente ineficiente, na medida em que sempre teremos mais do mesmo, embora, a ação possa apresentar diferentes roupagens.

Refletir criticamente sobre o problema do repertório não implica na negação daquilo que já está consolidado, nem tampouco se confunde com a simples deformação ou reproposição do vocabulário de movimentos existente. Mas, sim, relaciona-se com a descoberta de formas específicas para fins específicos, a construção de códigos capazes de se organizarem na linguagem que se almeja produzir. Só é possível estar em paz com o repertório existente quando não atribuímos a ele possibilidades infinitas, como se o que nele está escolhido fosse suficiente, independentemente daquilo que se pretende discutir, concedendo-lhe uma potência comunicativa universal.

\section{O MOVIMENTO EXPRESSivo}

Aqui, o argumento que será apresentado parte de duas premissas: 1) em nosso universo tudo move; e, 2) se há corpos, há movimento. Ao refletir sobre elas, a primeira constatação é a de que esses movimentos não são aleatórios, ao contrário, todos contêm algum propósito e estão submetidos às suas próprias leis; sejam eles corpos cosmológicos, geológicos ou biológicos. Trata-se, então, de entender o movimento como realidade física e, assim sendo, é aconselhável que propósitos não sejam confundidos com fins, nem tampouco se- 
jam limitados aos meios através dos quais um fim determinado é atingido. É preciso escapar dessa dualidade entre meios e fins. Um corpo que corre é um ambiente onde tanto a possibilidade de correr quanto a finalidade de continuar correndo se realizam concomitantemente. A segunda constatação diz respeito ao fato de que os corpos nos contam aquilo que realizam, a lua nos conta que orbita a terra, um corpo que anda conta que está andando, mas temos que considerar que há uma diferença inegável entre um movimento celestial e um movimento humano. Deste modo, impõe-se a questão da localidade dessa diferenciação.

Talvez, a mais relevante das diferenças entre os corpos, sobretudo, por trazer a questão da expressividade/comunicabilidade, é a de que no humano e, por uma questão lógica, no vivo, o movimento se faz gesto. E a dança enquanto produção humana, obviamente, se encontra condicionada a esta hipótese, na medida em que é um meio que carrega em si mesmo o seu fim. Para o filósofo político Giorgio Agamben (2015): ${ }^{5}$

Uma finalidade sem meios é tão alienante quanto uma medialidade que só tem sentido em relação a um fim. Se a dança é gesto, é porque ela não é, ao contrário, nada mais do que a sustentação e a exibição do caráter medial dos movimentos corporais. O gesto é a exibição de uma medialidade, o tornar visível um meio como tal. (AGAMBEM, 2015, p.59)

Formular possíveis enfoques para as dramaturgias da dança implica em dar adeus a toda e qualquer premissa que enuncia a existência de um sentido que transcende à materialidade do corpo em movimento e assumir que suas potenciais possibilidades expressivas e comunicacionais se encontram encarnadas naquilo que o gesto exibe. "O gesto é, nesse sentido, comunicação de uma comunicabilidade. Ele não tem especificamente nada a dizer, porque aquilo que mostra é o ser-na-linguagem do homem como pura medialidade". (Idem, 2015, p.60).

Outra diferença, não menos importante, na medida em que viabiliza a possibilidade da produção das linguagens em dança, é a de que temos corpos que possuem um sistema chamado sensório-motor. Obviamente, aqui, esse sistema será tratado fora das habituais dualidades entre estímulos e respostas, em que a percepção é apenas uma informante e o movimento apenas o executor das ordens provenientes de um comando central. De acordo com filósofo da mente Alva Noë, 'a percepção não é algo que acontece ao e no corpo, mas, sim, algo que o corpo faz". Para ele, a percepção e a autopercepção dependem das capacidades de agir e pensar, assim, propõe que a percepção
5 ACANBEM, Giorgio. Meios sem fim: notas sobre a política. Belo Horizonte: Autêntica, 2015. 
é um tipo de atividade pensante que não está confinada a um processo exclusivamente cerebral, mas, sim, que se trata de uma atividade do corpo como um todo. É disso que a semioticista e teórica da dança Helena Katz (2005) ${ }^{7}$ está falando quando diz que a dança é o pensamento do corpo.

\section{O SENTIDO DO MOVIMENTO}

Quando o assunto é o corpo que dança e que tem no gesto/movimento o seu meio, proponho a relevância de duas questões: a) qual o entendimento de movimento será adotado? $\mathrm{E}$ b) quais as especificidades cognitivas do movimento?

Até o início do século 20, o movimento foi estudado como sendo um fenômeno audiovisual, na medida em que, segundo as hipóteses vigentes, ele se daria pelo sequenciamento de posturas corporais topologicamente armazenadas na memória. Os estudos propunham a existência de um esquema motor, em que as relações entre a percepção e a ação obedeceriam a um plano de ação definido a partir de experiências passadas. Dentro dessa perspectiva, todo o processo de regulação dos movimentos estaria condicionado exclusivamente à atividade cerebral, responsável pela predição, preparação, execução, controle e redirecionamento de respostas previamente armazenadas. Hoje, a noção de esquema corporal encontra-se completamente modificada, passando a ser entendido como um conjunto de relações que envolvem tanto a sensação do movimento quanto a sua execução. Planos previamente definidos não são absolutos, a proposta é de que o movimento se dá como um conjunto de preferências cognitivas, passíveis de se atualizarem nas experiências recentes.

Para o neuropsicólogo Alain Berthoz, ${ }^{8}$ o movimento é o sexto sentido do corpo e integra atividades multissensoriais que operam a partir de pré-disposições selecionadas pela espécie, um sentido capaz de simular as ações corporais antes de colocá-las no mundo. Para ele, a percepção é ativa e a ação reconfigura a percepção; em outras palavras, trata-se de um ciclo contínuo em que percepção e ação são constantemente replanejadas a cada milésimo de segundo para que o corpo se adapte às circunstâncias imediatas. Deste modo, não cabe ao cérebro o controle absoluto dos movimentos, sua participação se dá a partir da realidade física e das propriedades formais do corpo, coordenando as informações provenientes do sentido do movimento de dois modos, ambos em sintonia com o mundo externo, a saber: a) de modo conservativo e contínuo; e, b) de modo projetivo, simulando a ação de maneira a predizer suas consequências e selecionando a melhor estratégia. Ou seja, o cérebro é sensível à velocidade do movimento e, assim, antecipa a condição futura do corpo em um contexto específico. Dado que as situações apresen-
7 KATZ, Helena. UM, DOIS, TRÊS. a dança é o pensamento do corpo. Belo Horizonte: Fid Editorial, 2005.

8 BERTHOZ, Alain. The Brain's sense of movement. Cambridge, Massachusetts: Harvard College, 2000. 
tadas pelo mundo são múltiplas e transitórias, seria ineficiente a ação de esquemas corporais inteiramente definidos.

O sentido do movimento possui receptores de sensibilidade que têm propriedades particulares, capazes de antecipar a ação por meio de processos de simulação (proprioceptores, tato e sistema vestibular). Um deles, os proprioceptores que irão detectar as variações de atividade na massa muscular e serão responsáveis pela regulação e adequação da força necessária à ação desejada. O corpo possui três tipos de receptores proprioceptivos, também conhecidos como receptores cinestésicos: 1) O fuso neuromuscular irá detectar o grau de estiramento do músculo, informando ao cérebro a sua posição e a sua velocidade de deslocamento, cabendo ao cérebro a ativação do músculo percebido em movimento; lembrando que o corpo humano possui mais de 600 músculos e que esse processo estará ocorrendo em todos eles contiguamente. O fuso tanto simula o movimento, devido à sua relação com os neurônios motores, quanto promove a adaptação da musculatura aos requisitos de algum movimento. E, 2) Os órgãos tendinosos de Golgi são receptores localizados nas junções dos músculos com os tendões e detectam a quantidade de força, e suas variações, empregada pela musculatura. O cérebro ordenará as informações provenientes de todas as articulações do corpo e projetará uma sucessão de derivações que dependem, e podem ser alteradas, de acordo com o contexto em que o movimento ocorre.

O tato, embora não possua receptores que informem a posição do corpo, eles [os receptores] também contribuirão com a regulação do tônus muscular ao detectar a pressão e a velocidade de um objeto sobre a pele.

Já o sistema vestibular perceberá, por meio de seus receptores gravito-inerciais, o movimento do corpo no espaço tanto no deslocamento quanto na imobilidade, por meio da aceleração angular e linear da cabeça. Os receptores angulares detectam a mudança da aceleração negativa e positiva da cabeça, são sensíveis às oscilações por ela sofridas durante o movimento. Já os receptores lineares são sensíveis à oscilação da gravidade, bem como à direção em que as forças gravitacionais agem sobre o corpo. O sistema vestibular possui uma conexão com os olhos e, através do reflexo vestíbulo-ocular, o cérebro será capaz de lidar com questões relacionais entre aceleração, velocidade, posição e precisão.

Julguei necessário, mesmo que de modo resumido, expor a complexidade envolvida nos movimentos realizados pelo corpo. Esses aspectos cognitivos favorecem que descartemos, de uma vez por todas, a ideia de que os movimentos são simplesmente cumpridores de tarefas prévias e racionalmente desenhadas por um comando central. 
Todos os sistemas que compõem o corpo irão se desenvolver e se configurar dependendo do uso que se faz deles; enfim, são passíveis de se especializarem, adquirindo altos níveis de complexidade pela repetição da experiência. No caso da dança, um fenômeno tátil-cinestésico em que a experiência de se mover se especializa.

\section{O CORPO QUE DANÇA}

Para os cientistas cognitivos George Lakoff e Mark Johnson (1999), ${ }^{9}$ as estruturas do cérebro se configuram pela implementação do projeto evolutivo e pela experiência do corpo no seu ambiente, sendo que o sistema sensório-motor tem um papel central nesse processo. Sem a percepção, e aqui se inclui o sentido do movimento, a racionalidade seria uma impossibilidade, isso porque, para eles, a percepção determina o modo como o sistema conceitual será construído e constituído. Assim, sem a experiência do corpo em seu ambiente, não haveria conceitos. Desta forma, a natureza e peculiaridade do corpo irão formatar as possibilidades de conceituação e categorização da experiência.

Cabe ressaltar que categorias não são recipientes que armazenam as informações. Para esses cientistas, todo o conhecimento se organiza em categorias, por meio delas somos capazes de reconhecer os objetos físicos, seus contornos, limites, direções e propriedades. Distinguir esses traços e suas relações espaciais (dentro/fora, atrás/à frente, em cima/embaixo, etc.) capacita o corpo a projetar e antecipar as ações e deslocamentos dos corpos no mundo. Por exemplo, em uma relação presa/predador, a presa tente a se comportar de modo imprevisível para garantir sua sobrevivência, quanto mais erráticos os seus deslocamentos maiores as suas chances. Contudo, as chances do predador estarão otimizadas devido à sua capacidade de antecipar as trajetórias que serão assumidas pela presa a partir das direções espaciais que o seu corpo indica. Desta forma, o corpo funda o modo como nos orientamos no espaço, não só em relação a ele mesmo, mas, também, na relação entre ele e os objetos.

O conhecimento adquirido pela experiência, ou seja, o resultado da ação perceptiva do corpo no mundo, irá se organizar em categorias gerais (p.ex.: veículos) e particulares (p.ex.: carros, trens, barcos, bicicletas, etc.). Nesta proposta do modo como o conhecimento é organizado, a dança será considerada como uma categoria geral, seus apreciadores serão capazes de reconhecê-la como tal; mas, entramos no campo do particular ao falarmos de piruetas, dado que, esse passo pertence a uma linguagem específica de dança.

Porém, além dos conhecimentos gerais e particulares, há, também, o conhecimento específico e especializado. O especialista terá o conhecimento dos níveis mais basais de uma categoria, ele reconhecerá suas propriedades cons-
9 LAKOFF, C. \& JOHNSON M Philosophy in the Flesh - the embodied mind and its challenge to western thought. New York: Basic Books, 1999 . 
titutivas e terá a capacidade de manipulá-las, desenvolvendo formas próprias de organizar esse conhecimento. Assim, o bailarino saberá como lidar com suspensão, linha, impulso, oposições e direções ao executar uma pirueta.

Para Lakoff e Johnson, quando esse conhecimento se organiza como linguagem, ele sempre será de natureza metafórica. O entendimento de metáfora, por eles proposto, não está restrito a ideia da figura de linguagem.

Nós descobrimos, ao contrário, que a metáfora está infiltrada na vida cotidiana, não somente na linguagem [verbal], mas também no pensamento e na ação. Nosso sistema conceptual ordinário, em termos do qual não só pensamos, mas também agimos, é fundamentalmente metafórico por natureza. (LAKOFF E JOHNSON, 2002, p.45). ${ }^{10}$

Se estivermos certos, ao sugerir que esse sistema conceptual é em grande parte metafórico, então o modo como pensamos, o que experienciamos e o que fazemos todos os dias são uma questão de metáfora. (Idem, p.46). ${ }^{11}$

Se as linguagens estão organizadas metaforicamente, é consequência natural entendermos que os processos de comunicação também estão. Uma metáfora significa alguma coisa em termos de outra, ela representa algo tanto para quem a exprime quanto para alguém que a acessa, ou seja, nossos sistemas conceituais partilham metáforas por meio da comunicação. "As metáforas são essenciais para conectar a linguagem (e assim a comunicação humana) e os circuitos cerebrais. É por meio das metáforas que as narrativas são construídas". (CASTELLS, 2017, p. 196). ${ }^{12}$ A comunicação acontece quando os cérebros são provocados e acionados no sentido de compartilhar ideias, conteúdos, argumentos e significados; cabendo aos processos metafóricos mediar essas trocas.

O corpo em movimento, no ato de dançar, tanto estabelece relações que já foram testadas anteriormente quanto explora outras possibilidades de organização do seu fazer. Seu treinamento o capacita a não somente especializar o sentido do movimento, sua orientação e domínio espaciais, mas, também, a propor outras espacialidades possíveis.

O modo como o corpo que dança organiza seu fazer é de natureza coreográfica e o movimento sempre será metafórico na medida em que abre outras possibilidades de conceituação nos processos de comunicação que aciona. Quando o assunto é o corpo em movimento produzindo linguagem no ambiente dança, torna-se necessário pensarmos que coreografia e dramaturgia
10 LAKOFF, G. \& JOHNSON M. Metáforas da Vida Cotidiana. São Paulo: Educ e Mercado de Letras, 2002.

11 Idem.

12 CASTELLS, Manuel. O Poder da Comunicação. Rio de Janeiro/São Paulo: Paz \& Terra, 2017 
são ocorrências indissociáveis e concomitantes à ação de dançar. Sem o entendimento de alguma proposição coreográfica, não temos como reconhecer sua dramaturgia. 